\title{
IMPACT OF DISTANCE LEARNING ON THE MOTOR ABILITIES OF PRIMARY SCHOOL-AGED PUPILS
}

\section{Donka Zheleva-Terzieva}

\begin{abstract}
:
The article compares the results of motor strength tests of primary school students to establish the impact of distance learning imposed by the authorities in the Republic of Bulgaria at the end of 2020 in order to limit the spread of COVID-19. The purpose of the present study is to determine whether educational tools affect the motor abilities of students. To achieve this goal, motor tests are conducted at the beginning of the school year and after the end of the online training.

Methods: The empirical methods used are tests to assess physical performance by jumping from a place with two legs to measure the explosive power of the lower limbs and throwing a solid ball to measure the explosive power of the upper limbs, shoulder girdle, and abdominal muscles. The statistical methods are the relative values of the structure - an absolute sum of the structural differences and integral coefficient of structural differences, as well as correlation and comparative analyzes.

Findings and results: The results of the experiment show that the strength achievements of students are not affected by the type of training.
\end{abstract}

UDC Classification: 378, DOI: https://doi.org/10.12955/pss.v2.247

Keywords: motor skills, primary school age, distance learning.

\section{Introduction}

COVID-19 was the reason for the confinement of people and particularly children in their homes for long periods of time, resulting in their physical activity decreased. The change in the way of learning deprives children of the opportunity to spend more time together, to meet, communicate, play sports and compete - all activities that in themselves can lead to changes in physical capacity (SchivachevaPineda, 2020).

Physical capacity is a set of potential opportunities for a person to realize effective motor activity. It is determined by the level of motor qualities (speed, strength, endurance, agility, and flexibility), which are elements of motor function and develop under the influence of various endogenous and exogenous factors (Boeva \& Ivanova, 2018). The improvement of motor qualities is characterized by the socalled "age dynamics associated with certain morphological and biological patterns in the development of organs and functions of the body. Almost $70 \%$ of the growth of the muscle strength considered in the article reaches the highest values between the ages of 7 and 11, that is, during the initial stage of the primary educational degree (Borisov et al., 2019).

Motor quality strength is "the person's ability to overcome or counteract external resistance through his muscle efforts" (Boeva \& Ivanova, 2018). Strength is a basic quality that underpins general physical training and significantly influences the manifestation of other motor qualities.

The test battery for measuring students' condition abilities, updated by a team of specialists from the National Sports Academy in 2019 (Miladinov et al., 2019), includes a total of five tests. Two of them are for measuring muscle strength: standing long jump with two legs to measure the explosive strength of lower limbs and throwing a dense ball with two hands up to measure the strength of upper limbs, shoulder girdle, and abdominal muscles.

In primary school age, during the winter months, priority is given to the quality 'strength', so this has raised the question: "Does the remote form of training in physical education and sport influence the level of development of motor quality strength and if so - to what extent?"

In a survey conducted in $2015 \mathrm{~K}$. Naydenova (2015) found that the significant stability of strength achievement in preschool children, who for the Republic of Bulgaria are in the age range 3-6-yearolds.

The relationship between the personal characteristics and the professional training of the teacher and the peculiarities in the development of the child's personality in the age of 7-11-year-olds is a guarantee to achieve high quality of the training of the students from primary school degree and to achieve lasting educational results. The rupture of the relation between teachers' vocational training and the educational development of students is a prerequisite for failures in training in the initial stage

\footnotetext{
${ }^{1}$ Trakia University, Faculty of Education, donkazeleva@gmail.com
} 
of primary education (Teneva, 2019). In this case, the role of the teacher of physical education and sport in online learning is considered an opportunity to influence the desire of students to develop their motor activity and physical capacity.

The objective of the present study is to conduct motor testing at the beginning of the school year and after the end of the distance form of education. The comparative analysis will be based on the processing of the obtained results of the two tests.

\section{Methodology}

The test diagnostics took place in September 2020 and February 2021 in the first and fourth grades of Zhelezik Secondary School - Stara Zagora. The persons surveyed were 9 girls and 11 boys from first grade and 14 girls and 10 boys from fourth grade. The contingent of this study is 44 persons and aims to establish the impact of distance learning on the development of motor quality strength.

Tests to assess the physical capacity of students are traditionally conducted at the beginning and end of the school year in the form of preliminary and final control. To achieve the objective of this study, the above-mentioned empirical method is applied in two variants - as an entry-level and as an intermediate test for the school year.

Test 1: "Standing long jump with two legs"

Place of venue: flat playground with non-slippery hard or hard-elastic flooring.

Method of conduct: the starting position is standing up, with the soles at the width of the shoulders, the toes - behind a drawn line, and the hands raised up and forward and strained in the elbows; flywheel movements are performed with the hands back and forth and jumping in the forward direction.

\begin{tabular}{|c|c|c|c|c|c|c|c|}
\hline $1^{\text {st }}$ test & $\begin{array}{l}2^{\text {nd }} \\
\text { test }\end{array}$ & \begin{tabular}{|l|} 
Difference, \\
points
\end{tabular} & $\begin{array}{l}\text { Integral } \\
\text { coefficient of } \\
\text { structural } \\
\text { differences } \\
\end{array}$ & $1^{\text {st }}$ test & $\begin{array}{l}2^{\text {nd }} \\
\text { test }\end{array}$ & $\begin{array}{l}\text { Difference, } \\
\text { points }\end{array}$ & $\begin{array}{l}\text { Integral } \\
\text { coefficient of } \\
\text { structural } \\
\text { differences } \\
\end{array}$ \\
\hline \multicolumn{4}{|c|}{ First grade - test 1} & \multicolumn{4}{|c|}{ First grade - test 2} \\
\hline 95 & 90 & -5 & 3.8 & 240 & 230 & -10 & 3.0 \\
\hline 130 & 125 & -5 & 2.8 & 280 & 300 & +20 & 4.8 \\
\hline 85 & 90 & +5 & 4.0 & 280 & 310 & +30 & 7.1 \\
\hline 90 & 85 & -5 & 4.0 & 230 & 245 & +15 & 4.5 \\
\hline 95 & 120 & +25 & 16.3 & 200 & 250 & +50 & 15.6 \\
\hline 75 & 95 & +20 & 16.5 & 280 & 300 & +20 & 4.8 \\
\hline 90 & 90 & 0 & 0 & 300 & 250 & -50 & 12.8 \\
\hline 95 & 110 & +15 & 10.3 & 240 & 235 & -5 & 1.5 \\
\hline 90 & 85 & -5 & 4.0 & 200 & 225 & +25 & 8.3 \\
\hline & Total & +45 & & & & +95 & \\
\hline \multicolumn{4}{|c|}{ Fourth grade - test 1} & \multicolumn{4}{|c|}{ Fourth grade - test 2} \\
\hline 128 & 140 & +12 & 6.3 & 580 & 650 & +70 & 8.0 \\
\hline 120 & 130 & +10 & 5.6 & 620 & 680 & +60 & 6.5 \\
\hline 130 & 120 & -10 & 5.6 & 610 & 650 & +40 & 4.5 \\
\hline 115 & 125 & +10 & 5.9 & 580 & 600 & +20 & 2.4 \\
\hline 105 & 130 & +25 & 14.9 & 550 & 540 & -10 & 1.3 \\
\hline 150 & 140 & -10 & 4.9 & 540 & 560 & +20 & 2.6 \\
\hline 150 & 145 & -5 & 2.4 & 540 & 560 & +20 & 2.6 \\
\hline 132 & 120 & -10 & 5.6 & 380 & 400 & +20 & 3.6 \\
\hline 140 & 135 & -5 & 2.6 & 400 & 420 & +20 & 3.4 \\
\hline 130 & 135 & +5 & 2.7 & 440 & 420 & -20 & 3.3 \\
\hline 145 & 120 & -25 & 13.3 & 580 & 500 & -80 & 10.5 \\
\hline 130 & 120 & -10 & 5.6 & 420 & 400 & -20 & 3.4 \\
\hline 173 & 160 & -13 & 5.5 & 580 & 640 & +60 & 6.9 \\
\hline 148 & 165 & +18 & 8.1 & 525 & 570 & +45 & 5.8 \\
\hline & Total & -8 & & & & +245 & \\
\hline
\end{tabular}

Source: Author 
Achievement: the distance from the jumping line to the place where the heels touch the ground measured using a pre-drawn field or a measuring roller with an accuracy of up to $1 \mathrm{~cm}$. Everyone has the right to two attempts, recording the better result.

Test 2: "Throwing a dense ball with two hands up"

Place of venue: flat playground with non-slippery hard or hard-elastic flooring.

Method of conduct: the starting position is a straddling position, with the toes behind a drawn line, and the hands covering the ball on the side-back with slightly parted fingers and holding the ball high above and slightly in front of the head; performed is a one-time bending of the body strongly backward and throwing the ball back and forth. Achievement: the distance from the throw line to the drop point of the ball using a pre-drawn field or a measuring roller with an accuracy of up to $5 \mathrm{~cm}$. Everyone has the right to two attempts, recording the better result.

Table 1 presents the results for the two groups of boys in both tests.

Note: The weight of the dense ball used in the first class is $1 \mathrm{~kg}$ and in the fourth $-3 \mathrm{~kg}$.

Table 2 presents the results for the two groups of girls in both tests.

\begin{tabular}{|c|c|c|c|c|c|c|c|}
\hline $1^{\text {st }}$ test & $\begin{array}{l}2^{\text {nd }} \\
\text { test }\end{array}$ & $\begin{array}{l}\text { Difference, } \\
\text { points }\end{array}$ & $\begin{array}{l}\text { Integral } \\
\text { coefficient of } \\
\text { structural } \\
\text { differences }\end{array}$ & $1^{\text {st }}$ test & $\begin{array}{l}2^{\text {nd }} \\
\text { test }\end{array}$ & $\begin{array}{l}\text { Difference, } \\
\text { points }\end{array}$ & $\begin{array}{l}\text { Integral } \\
\text { coefficient of } \\
\text { structural } \\
\text { differences }\end{array}$ \\
\hline \multicolumn{4}{|c|}{ First grade - test 1} & \multicolumn{4}{|c|}{ First grade - test 2} \\
\hline 95 & 90 & -5 & 3.8 & 240 & 230 & -10 & 3.0 \\
\hline 130 & 125 & -5 & 2.8 & 280 & 300 & +20 & 4.8 \\
\hline 85 & 90 & +5 & 4.0 & 280 & 310 & +30 & 7.1 \\
\hline 90 & 85 & -5 & 4.0 & 230 & 245 & +15 & 4.5 \\
\hline 95 & 120 & +25 & 16.3 & 200 & 250 & +50 & 15.6 \\
\hline 75 & 95 & +20 & 16.5 & 280 & 300 & +20 & 4.8 \\
\hline 90 & 90 & 0 & 0 & 300 & 250 & -50 & 12.8 \\
\hline 95 & 110 & +15 & 10.3 & 240 & 235 & -5 & 1.5 \\
\hline \multirow[t]{2}{*}{90} & 85 & -5 & 4.0 & 200 & 225 & +25 & 8.3 \\
\hline & Total & +45 & & & & +95 & \\
\hline \multicolumn{4}{|c|}{ Fourth grade - test 1} & \multicolumn{4}{|c|}{ Fourth grade - test 2} \\
\hline 128 & 140 & +12 & 6.3 & 580 & 650 & +70 & 8.0 \\
\hline 120 & 130 & +10 & 5.6 & 620 & 680 & +60 & 6.5 \\
\hline 130 & 120 & -10 & 5.6 & 610 & 650 & +40 & 4.5 \\
\hline 115 & 125 & +10 & 5.9 & 580 & 600 & +20 & 2.4 \\
\hline 105 & 130 & +25 & 14.9 & 550 & 540 & -10 & 1.3 \\
\hline 150 & 140 & -10 & 4.9 & 540 & 560 & +20 & 2.6 \\
\hline 150 & 145 & -5 & 2.4 & 540 & 560 & +20 & 2.6 \\
\hline 132 & 120 & -10 & 5.6 & 380 & 400 & +20 & 3.6 \\
\hline 140 & 135 & -5 & 2.6 & 400 & 420 & +20 & 3.4 \\
\hline 130 & 135 & +5 & 2.7 & 440 & 420 & -20 & 3.3 \\
\hline 145 & 120 & -25 & 13.3 & 580 & 500 & -80 & 10.5 \\
\hline 130 & 120 & -10 & 5.6 & 420 & 400 & -20 & 3.4 \\
\hline 173 & 160 & -13 & 5.5 & 580 & 640 & +60 & 6.9 \\
\hline 148 & 165 & +18 & 8.1 & 525 & 570 & +45 & 5.8 \\
\hline & Total & -8 & & & & +245 & \\
\hline
\end{tabular}

Source: Author

The integral coefficient of structural differences (Arkadiev, 2003) measures the number of changes in the compared structures. After the detailed discussion of the structure and structural differences between the two tests in the form of entry and intermediate control, some summaries can be made for the students surveyed:

- the range of the difference between the results of the two tests is from -80 to +110 points. Worth noting are single cases with a negative sign of 20, 50, and 80 units; 
- the majority of the differences are in favor of the final test carried out in the form of intermediate control (the results have greater output values than at the input);

- the highest increase rates were observed in the achievements of fourth-grade boys in Test 2, followed by girls from the fourth grade in Test 2 and boys in the first grade in Test 2;

- the maximum value of the integral coefficient of structural difference reaches 16.9 points.

After the detailed discussion of the differences in the different groups of subjects examined specified with the test results, the following summaries can be made for the subjects under consideration:

- all great values with a negative sign are recorded for the girls;

- most of the greater positive-sign increase values are observed in Test 2 for the boys;

- for all the persons surveyed, including 21 boys and 23 girls, in both tests, seven results had a minus sign for the boys and eighteen for the girls. Three results for boys and one for girls are without change;

- the only aggregated result with a negative sign is observed in the achievements of girls in the fourth-grade of Test 1, and the largest increase in results is recorded in boys in the fourth grade of Test 2. In the same age group on the same test, girls recorded the second largest aggregate increase;

- Test 2, which measure the explosive force of the upper limbs, shoulder girdle, and abdominal muscles, are encouraging. The positive Test 1 indicators showed the results of three of the four test groups studied.

In summary, there is some difference in the input and output of students.

A Pearson simple linear correlation coefficient is calculated to determine the closeness of the relationship between the results of the two test checks. Table 3 shows the values of the coefficient for the results of Test 1 and Test 2, the statistical processing of which was performed by and measured at a significance with a probability $<0.01$.

\begin{tabular}{|l|r|}
\hline Table 3: Pearson's correlation coefficient & 0.861 \\
\hline $\mathbf{1}^{\text {st }}$ test & 0.976 \\
\hline $\mathbf{2}^{\mathbf{2} \text { test }}$ & \\
\hline Source: Author & \\
\hline
\end{tabular}

The correlation coefficient values determine a large dependence (correlation) of the measured connection in Test 1 and a very large dependence of the measured connection in Test 2 . This shows that student's strength indicators depend more on their own abilities than on the type of training.

\section{Conclusion}

Following the study on the impact of distance learning on the motor abilities of primary school-aged pupils, it was found that there was no deterioration or retention at the same level of indicators reflecting motor quality strength. The growth of indicators reflecting the degree of motor quality strength in most groups is positive. The results show that the indicators are massively improved, especially in the test, which measures the explosive strength of the upper extremities, shoulder girdle, abdominal muscles. The trend marks an upward performance dynamics, but the indicators don't depend on the type of learning process.

\section{References}

Arkadiev, D. (2003). Statistics, Textbook for students of economic specialties. Stara Zagora, ISBN 954-9887-38-3.

Boeva, B., V. Ivanova (2018). Theory and methodology of physical education. Textbook for students from Trakia University, Part One: Theoretical and Methodological Basis of Physical Education. Stara Zagora: Publ. Faculty of Education, Trakia University.

Borisov, L., etc. (2019). Study on certain aspects of physical capacity in 6-18-year-old students over a 60 years. Sofia: Yearbook of Vasil Levski National Sports Academy, 1.

Miladinov, O., etc. (2019). System for assessing the physical capacity of students from 1st to XII ${ }^{\text {th }}$ grade. Sofia: NSA Press. Naydenova, K. (2015). Influence of physical education and sports activities on motor quality strength in preschool children. Sport and science, 2, 117-122.

Teneva, M. (2019). Attempt to justify a professional gram of the primary teacher $\left(1^{\text {st }}-4^{\text {th }}\right.$ grade). Pedagogy, 91 ( 2$)$, $202-$ 211

Shivacheva-Pineda, I. (2020). The relation health education - pandemic. Yearbook of the Faculty of Education, XVII, 142153 